\title{
Correction to: Modeling the inactivation of Lactobacillus brevis DSM 6235 and retaining the viability of brewing pitching yeast submitted to acid and chlorine washing
}

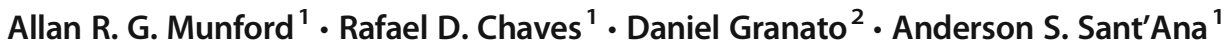 \\ Published online: 11 June 2020 \\ (C) Springer-Verlag GmbH Germany, part of Springer Nature 2020
}

Correction to: Applied Microbiology and Biotechnology (2020) 104:4071-4080 https://doi.org/10.1007/s00253-020-10534-x

There is an error in the original publication of this paper for the below data was missed by author. It should be under "Conflict of interest" statement.

A patent application (pending) (BR 102016013836 1; WO2017214690A1) included results from this paper. The authors declare that no other conflict of interest exists.

Publisher's note Springer Nature remains neutral with regard to jurisdictional claims in published maps and institutional affiliations.

The online version of the original article can be found at https://oi.org/ 10.1007/s00253-020-10534-x

Anderson S. Sant'Ana

and@unicamp.br

1 Department of Food Science, Faculty of Food Engineering,

University of Campinas, Campinas, SP, Brazil

2 Food Processing and Quality, Innovative Food System Unit, Natural Resources Institute Finland (Luke), FI-02150 Espoo, Finland 